\title{
Bidirectional Quadratic Converter-Based PMBLDC Motor Drive for LEV Application
}

\author{
Mukesh Kumar $\mathbb{D}^{1},{ }^{1}$ Kalpana Chaudhary $\mathbb{D}^{1},{ }^{1}$ R. K. Saket $\mathbb{D}^{1},{ }^{1}$ and Baseem Khan $\mathbb{D}^{2}$ \\ ${ }^{1}$ Department of Electrical Engineering, Indian Institute of Technology (BHU), Varanasi, India \\ ${ }^{2}$ Department of Electrical and Computer Engineering, Hawassa University, Hawassa, Ethiopia \\ Correspondence should be addressed to Baseem Khan; baseem.khan04@gmail.com
}

Received 4 November 2021; Revised 20 December 2021; Accepted 30 December 2021; Published 17 January 2022

Academic Editor: Hamdy Soltan

Copyright (C) 2022 Mukesh Kumar et al. This is an open access article distributed under the Creative Commons Attribution License, which permits unrestricted use, distribution, and reproduction in any medium, provided the original work is properly cited.

\begin{abstract}
In this study, a bidirectional DC-to-DC quadratic converter (BDQC) is designed and developed for the motoring and regenerative braking (RB) of a permanent magnet brushless DC (PMBLDC) motor for a light electric vehicle (LEV) application. A PMBLDC motor is deemed more suitable for an electric vehicle (EV) due to its high efficiency and torque density. In the present work, a $\mathrm{BDQC}$ of $1 \mathrm{~kW}$ is designed to drive a 1.1 HP PMBLDC motor through a conventional voltage source inverter (VSI). An EV's load cycle is emulated using a highly inertial load driven by a PMBLDC motor during the converter's boost mode operation. RB is a crucial factor in extending the driving range of EVs by efficiently utilizing battery power. The converter operates in buck mode during RB, and simultaneously, the back electromotive force (EMF) of the PMBLDC machine is boosted by the self-inductance of the PMBLDC motor and the VSI. The braking technique used in this work eliminates the traditional drawback of RB in buck mode, as the power is extracted even when the motor's back EMF is lower than the battery's voltage. The control strategy has been implemented using the TMS320F28335 DSP controller for a developed converter prototype of the converter and driving the PMBLDC motor. The experimental results are compared to the simulation results, and a good alignment has been found.
\end{abstract}

\section{Introduction}

In recent years, electric vehicles (EVs) have drawn more attention as a substitute for conventional internal combustion engine (ICE) vehicles. With the advancement of batteries and motors, EVs have become an optimistic substitute for ICE vehicles. Due to its high efficiency and controllability, the PMBLDC motor is the most popular option in the drive train of low-to-medium power EVs. In the past decade, to improve the drivetrain's efficiency, research on bidirectional DC-to-DC converters (BDCs) for EV applications has been extensively done [1-5]. The problem with these BDCs is that they have a large number of component requirements and high voltage stress on the switches. The leakage inductance of the transformer also causes high voltage stress on the switches. Different types of nonisolated and isolated bidirectional DC-DC converters have been introduced. A half-bridge type converter with more components, high voltage stress on switches, and a high-frequency transformer is used [6]. A full-bridge type converter with low voltage gain, a large number of power switches, and a transformer are required for isolation $[7,8]$. The leakage inductance of the transformer causes high voltage stress on switches. Another isolated converter of fullbridge with flyback snubber has high voltage gain, but two transformers are used, which have leakage inductance. Leakage inductance causes high voltage stress on switches [9]. A clapping circuit is used to reduce the voltage and current stress. The converter becomes more complex and difficult to control. Recently, a different type of nonisolated double boost-flyback converter has been proposed in $[10,11]$. The voltage gain is high in a double boost converter, but it requires two coupled inductors, and there is no common ground between input and output.

The various nonisolated bidirectional DC-to-DC converters have been compared based on their performance 
$[12,13]$. The voltage gain of the converter is two times that of a conventional buck-boost converter. A modified nonisolated BDC for improved performance and efficiency is presented in $[14,15]$. In this case, the efficiency is improved, but the voltage gain is the same as with the conventional buck-boost converter. The study on the bidirectional power flow using the VSI was done in [16-18]. The converter requires a large number of power switches and imposes high voltage stress on the switches. A three-port DC-DC converter based on quadratic boost operation for stand-alone PV/battery systems is presented [19]. Recent research focuses on the modified converters because they are nonisolated (transformerless) topologies. Therefore, the converter's size, weight, and cost are reduced as presented in $[20,21]$. The quadratic converters have high voltage gain, thereby having more efficiency than conventional ones [22-24]. Regenerative braking can be achieved by reversing power flow from the battery to the PMBLDC motor. It can be done even at low back EMF by boosting it using the selfinductance of the PMBLDC motor by controlling the switches of VSI described in $[25,26]$. The back EMF boost is controlled by switches using a hall sensor. The signal from the hall sensor will give the information for the switches to be ON or OFF.

The electrical system of a powertrain configuration for an $\mathrm{EV}$ is shown in Figure 1. The magnitude and direction of the power are controlled by the BDQC. Controlled electrical power flows between the battery and the PMBLDC motor. The BDQC operates in two modes: motoring (boost) and regenerative braking (buck) mode. In the motoring mode, electrical power flows from the battery to the PMBLDC motor through VSI. Simultaneously, the kinetic energy of the PMBLDC motor is converted into electrical energy and fed back to the battery through the bidirectional VSI during regenerative braking. In turn, a converter with fewer components has lower losses and is needed to fulfill the requirements of high efficiency and significant voltage gain in EVs. A comparison of different bidirectional converters with different parameters is given in Table 1.

The presented nonisolated BDQC has a simple topology, control strategy, and a large voltage gain, which ensures wide voltage range operation when compared to conventional bidirectional buck or boost converters. The topology of the BDQ buck-boost converter is shown in Figure 2. Four switches with antiparallel diodes have been implemented in this BDC. The number of components can be reduced by using the back diodes of the MOSFETs [27]. A battery with a voltage of $V_{i}$ is connected on the low voltage side, and the DC link, or the motor side voltage, is $V_{o}$. The inductor in series with the battery is $L_{1}$, and the inductor in the middle is $L_{2}$. The capacitor in the center is $C_{1}$, while the DC link capacitor is $\mathrm{C}_{2}$.

In this work,

(i) An efficient regenerative technique with the help of the self-inductance of the PMBLDC motor is presented

(ii) An optimum switching technique is employed for operating the converter at reduced switching losses (iii) A back EMF boosting technique is used to extract power even at low motor speed

(iv) The developed system's designing, simulation, and hardware validation are performed

This study describes the BDQC operation in motoring and regenerative braking modes. The motoring mode of operation is discussed in Section 2, and the regenerative braking mode of operation is given in Section 3. The design parameters of the converter are presented in Section 4. Simulation results and validation results through a developed prototype are explained in Sections 5 and 6, respectively. The conclusion is made in Section 7.

\section{Motoring Mode of Operation}

The converter is designed to operate in the continuous inductor current mode (CICM) in steady-state as well as in low load conditions. The capacitors $C_{1}$ and $C_{2}$ are sufficient to maintain a steady voltage during one period of switching $\left(T_{\mathrm{s}}\right)$. In motoring mode operation, the switches $S_{1}$ and $S_{4}$ are OFF, switch $S_{3}$ is always turned $\mathrm{ON}$ to avoid switching losses, and switching of switch $S_{2}$ is controlled with PWM to execute the boosting operation. The following two modes can explain the converter's motoring (boost) mode operation.

2.1. Mode $1\left(0, T_{\text {on }}\right)$. The switches $S_{2}$ and $S_{3}$ are ON for time intervals 0 to $\mathrm{DT}_{\mathrm{S}}$, and $S_{1}$ and $S_{4}$ are OFF. In this mode, the energy stored in the capacitor $C_{1}$ is transferred to the inductor $L_{2}$, and the battery voltage $V_{i}$ charges the inductor $L_{1}$, as shown in Figure 3.

2.2. Mode $2\left(T_{\text {on }}, T_{s}\right)$. In this mode, $S_{3}$ is $\mathrm{ON}$, and the rest three switches are OFF for time interval (1-D) $T_{s}$. During this mode, the inductor $L_{2}$ transfers its stored energy to the DC link capacitor $C_{2}$, and capacitor $C_{1}$ is being charged by inductor $L_{1}$, as shown in Figure 4 . The converter's boost mode operating principle in steady-state is shown in Figure 5.

For these two modes of boost operation, the volt-sec balance principle across inductors $L_{1}$ and $L_{2}$ with $C_{1}$ at voltage $V_{\mathrm{c} 1}$ yields the following equations:

$$
\begin{gathered}
D T_{s} V_{i}+(1-D) T_{s}\left(V_{i}-V_{c 1}\right)=0, \\
D T_{s} V_{c 1}+(1-D) T_{s}\left(V_{c 1}-V_{o}\right)=0 .
\end{gathered}
$$

By eliminating $V_{\mathrm{cl}}$ from (1) and (2), the voltage gain in boost mode is obtained as

$$
\frac{V_{o}}{V_{i}}=\frac{1}{(1-D)^{2}},
$$

where $D=T_{\text {on }} / T_{s}$ is the duty ratio, and the quadratic nature of the converter can be inferred from (3). 


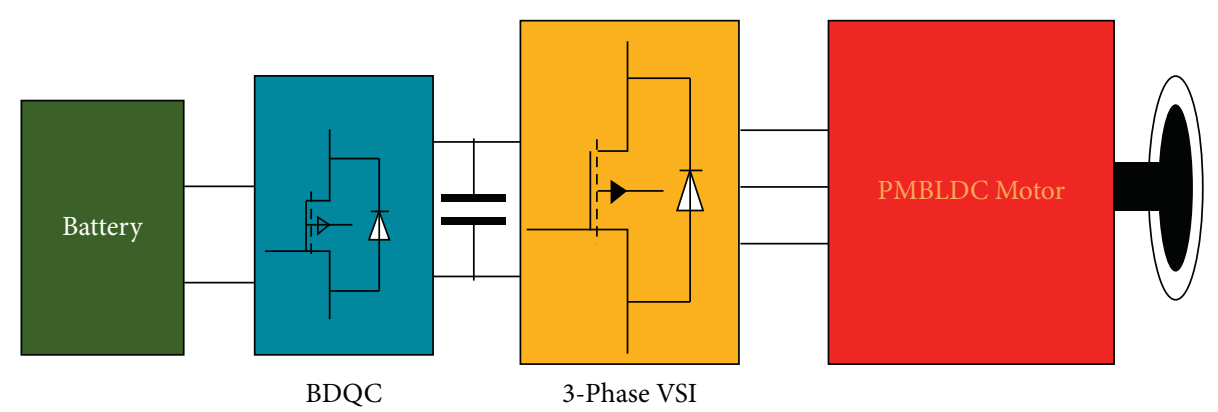

FIGURE 1: Schematic of the electrical system of the powertrain in EVs.

TABLE 1: Comparison of different bidirectional converters.

\begin{tabular}{|c|c|c|c|c|c|}
\hline Converter & Component count & $\begin{array}{l}\text { Voltage ratio step- } \\
\text { up }\end{array}$ & $\begin{array}{l}\text { Voltage ratio } \\
\text { step-down }\end{array}$ & Voltage stress on power switches & Efficiency (\%) \\
\hline $\begin{array}{l}\text { Converter in } \\
1\end{array}$ & $\begin{array}{c}3 \text { inductors, } 5 \text { capacitors, } 5 \\
\text { power switches }\end{array}$ & $2+D / 1-D$ & $D / 3-D$ & $\begin{array}{c}(1+M) V_{H} / 3 M \\
2(1+M) V_{H} / 3 M, \text { where } \\
M=V_{H} / V_{L}\end{array}$ & 96.67 \\
\hline $\begin{array}{l}\text { Converter in } \\
3\end{array}$ & $\begin{array}{l}1 \text { inductor, } 1 \text { transformer, } 3 \\
\text { capacitors, } 6 \text { power switches }\end{array}$ & $\begin{array}{l}N /(1-D)^{2} \\
N=N 1 / N 2\end{array}$ & $(1-D)^{2} / N$ & $(-D) V / N V / N(N V) /(1-D)^{2}$ & 95.4 \\
\hline $\begin{array}{l}\text { Converter in } \\
5\end{array}$ & $\begin{array}{l}2 \text { inductors, } 1 \text { transformer, } 2 \\
\text { capacitors, } 9 \text { power switches }\end{array}$ & $n V_{L} /\left(1-2 D_{S T}\right)$ & & $V_{L} /\left(1-2 D_{S T}\right)$ & 97 \\
\hline $\begin{array}{l}\text { Converter in } \\
15\end{array}$ & $\begin{array}{c}1 \text { inductor, } 3 \text { capacitors, } 4 \text { power } \\
\text { switches }\end{array}$ & $2 / 1-D$ & $D / 2$ & ----- & 92.5 \\
\hline BDQC & $\begin{array}{l}2 \text { inductors, } 2 \text { capacitors, } 4 \\
\text { power switches, } 2 \text { power diodes }\end{array}$ & $1 /(1-D)^{2}$ & $D^{2}$ & $V_{i} / 1-D V_{i} /(1-D)^{2}$ & 95.4 \\
\hline
\end{tabular}

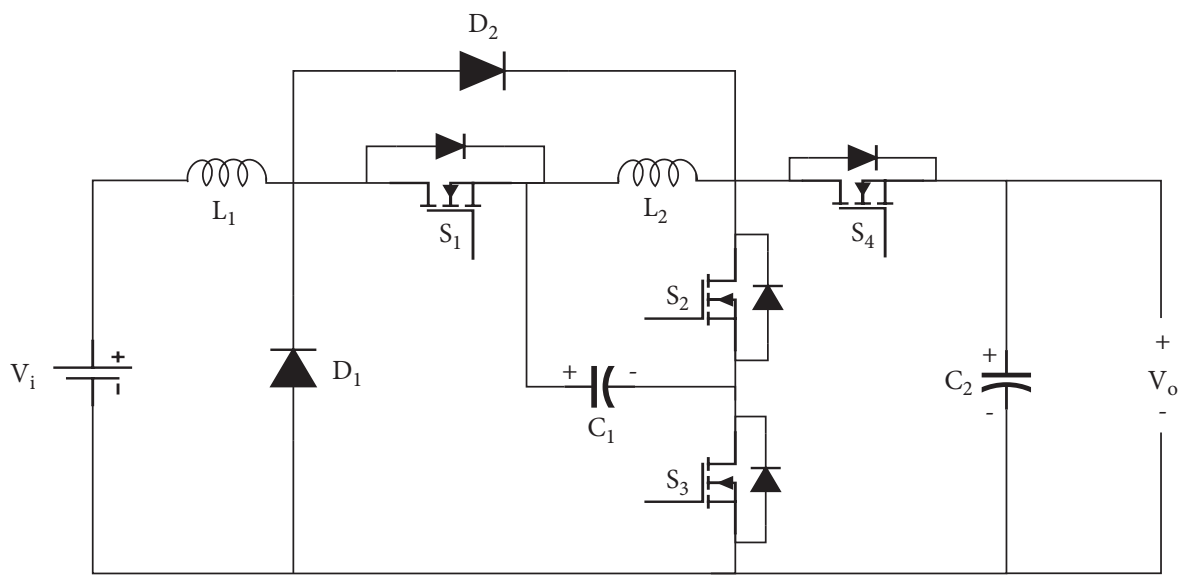

FIgURE 2: Bidirectional DC-DC quadratic converter.

\section{Regenerative Braking Mode of Operation}

The converter's braking (buck) mode is employed to perform $\mathrm{RB}$, and this allows the mechanical energy stored in the inertial load and the rotor of the PMBLDC motor to be transferred back to the source. In the braking (buck) mode operation, the switches $S_{1}$ and $S_{4}$ are controlled with PWM simultaneously. The switches $S_{2}$ and $S_{3}$ are OFF throughout this mode of operation. The braking (buck) mode can be described in two stages of operation. These operations have been explained briefly in subsequent subsections.
3.1. Mode $1\left(0, T_{\text {on }}\right) . S_{1}$ and $S_{4}$ are $\mathrm{ON}$ for the time interval 0 to $\mathrm{DT}_{\mathrm{s}}$ in mode 1 of the buck operation. During this time interval, current in $L_{1}$ and $L_{2}$ increases, as inductors are being charged by capacitors $C_{1}$ and $C_{2}$, respectively, as shown in Figure 6.

3.2. Mode $2\left(T_{\text {on }}, T_{S}\right)$. All the switches $S_{1}, S_{2}, S_{3}$, and $S_{4}$ are OFF for the time interval (1-D)Ts. The stored energy of inductor $L_{1}$ is transferred to the battery at voltage $V_{i}$ and energy of inductor $L_{2}$ to capacitor $C_{1}$. The load at voltage $V_{o}$ 


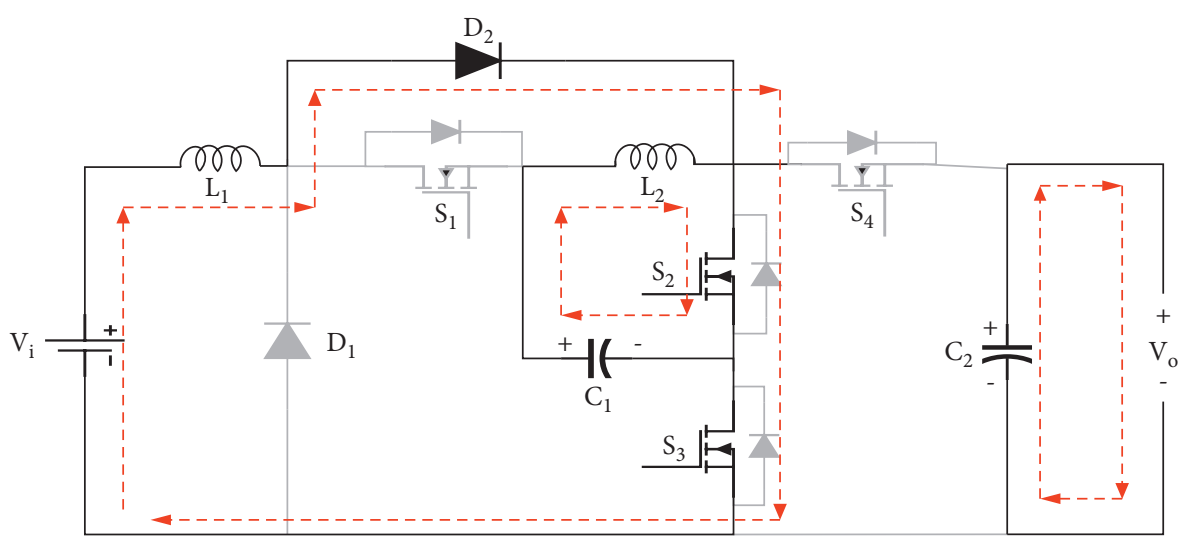

FIgURE 3: Converters' boost mode operation in mode 1.

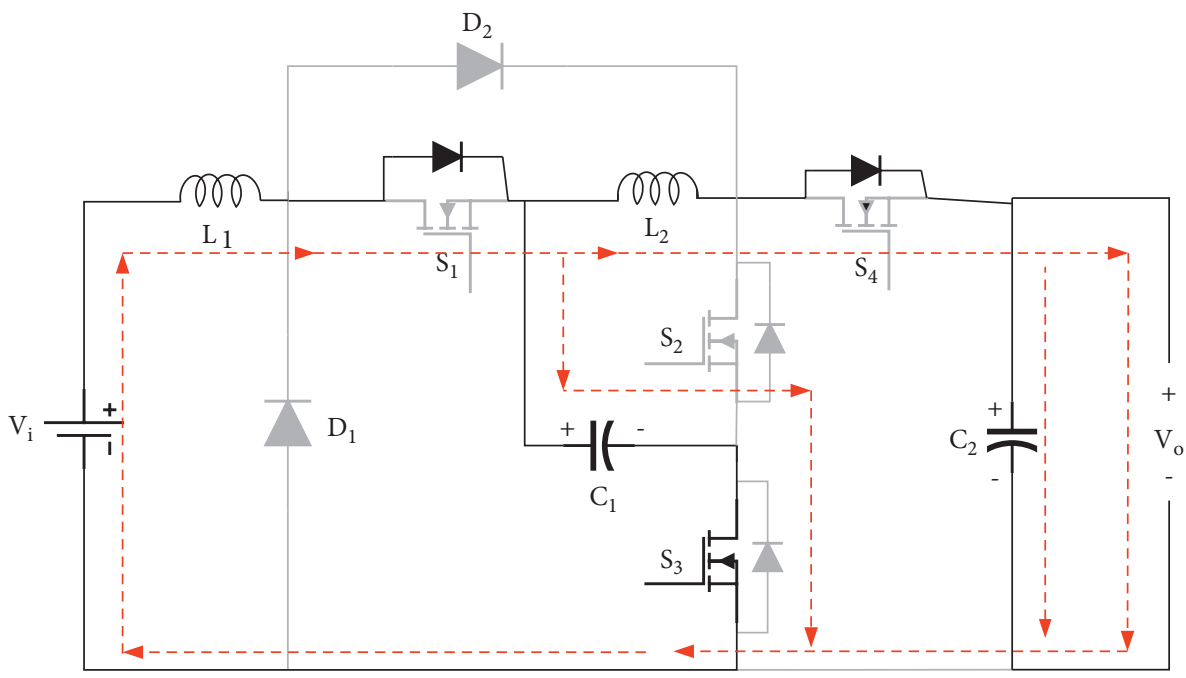

Figure 4: Converters' boost mode operation in mode 2.

is feeding the regenerated energy to capacitor $C_{2}$, as shown in Figure 7.

The waveforms of inductor currents and voltages are shown in Figure 8. For these two modes of operation, the voltage across the capacitor $C_{1}$ is assumed as $V_{\mathrm{c} 1}$.

The volt-sec balance principle across the inductors $L_{1}$ and $L_{2}$ gives the following equations:

$$
\begin{gathered}
D T_{s}\left(V_{c 1}-V_{i}\right)+(1-D) T_{s} V_{i}=0, \\
D T_{s}\left(V_{c 1}-V_{o}\right)+(1-D) T_{s} V_{c 1}=0 .
\end{gathered}
$$

By eliminating $V_{\mathrm{cl}}$ from (4) and (5), the converter gain is obtained as a function of $D$ as follows:

$$
\frac{V_{i}}{V_{o}}=D^{2}
$$

(6) shows that the converter buck mode voltage gain is quadratic in nature.

3.3. Working of VSI during Regenerative Braking. In the RB (buck) mode, energy flow from the PMBLDC motor to the battery is required. Only by controlling the converter, the mechanical energy cannot be transferred from the PMBLDC motor, and the motor needs to be operated in the second quadrant. Instead of direct rectification, a back EMF boosting technique is applied in this work during regenerative braking.

The self-inductances of the PMBLDC motor are charged by shorting all the three phases together. The stored energy in these inductances is transferred to the converter's output capacitor $\left(C_{2}\right)$ by turning OFF all switches of VSI. A flow diagram showing the converter operation based on the driver's on-road decision is shown in Figure 9. The equivalent circuit of the two active phases of the VSI during regenerative braking is shown in Figure 10. The back EMF, armature current of the PMBLDC motor, and switching signal of VSI are shown in Figure 11.

\section{Converter Design}

The converter design is done as per the boost and buck operations, as shown in Figure 5 and Figure 8. The designed converter is thus operated in the CICM, and the output 


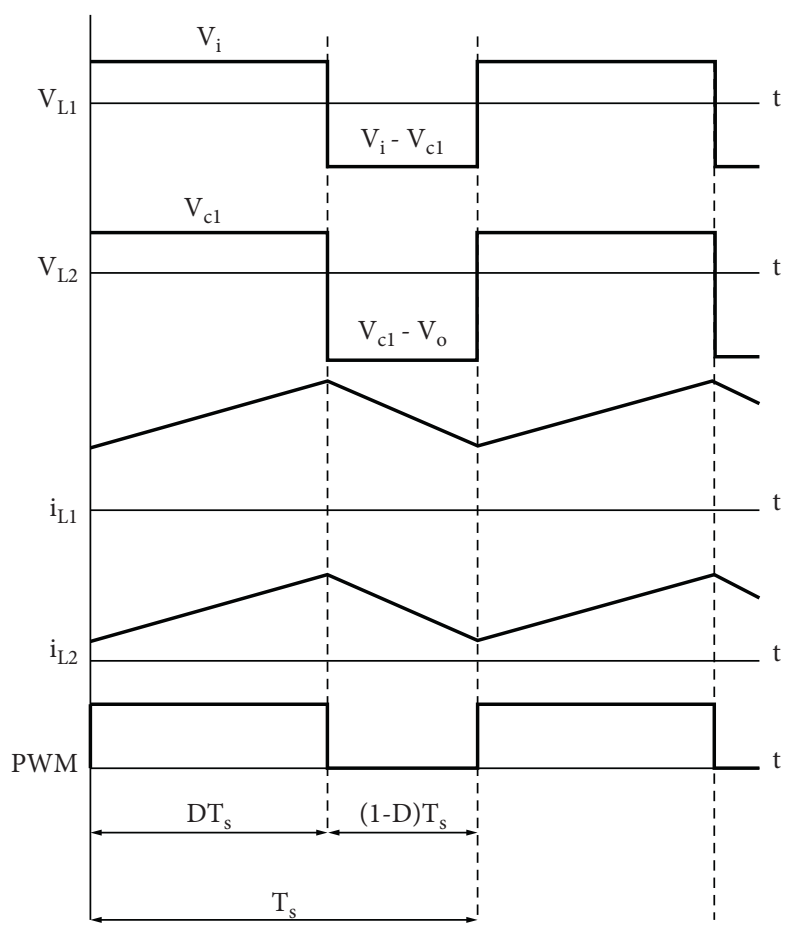

FIgURE 5: Converter's buck mode operation, mode 2.

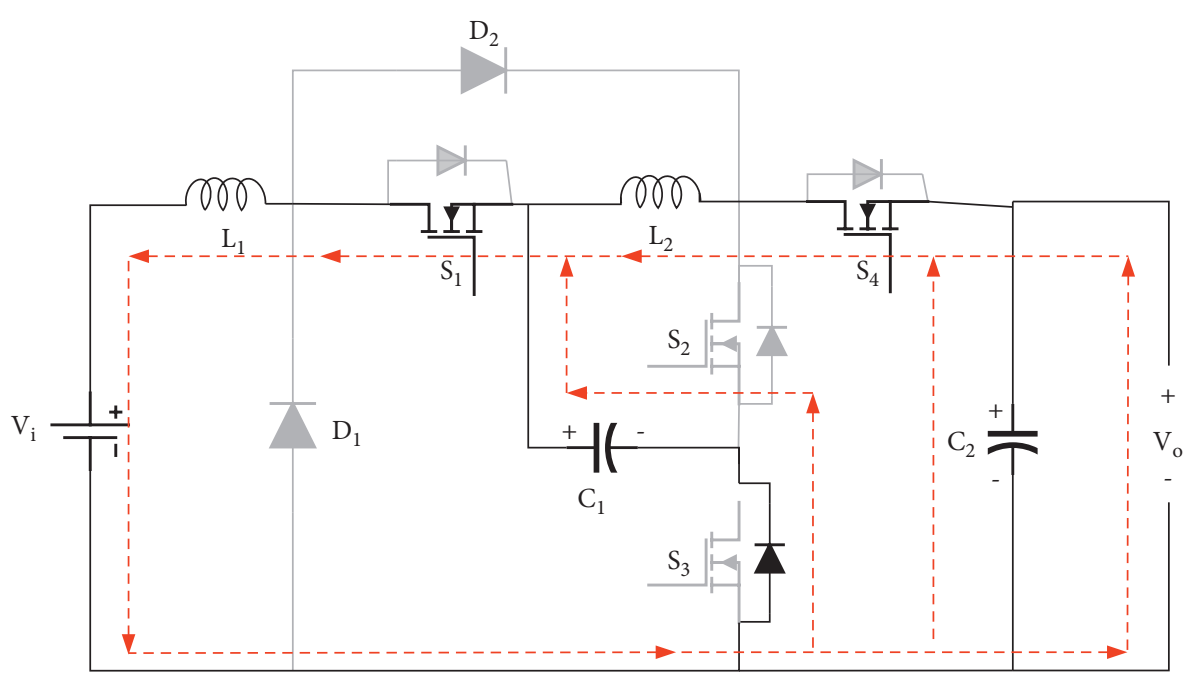

FIGURE 6: Convers' buck mode operation in mode 1.

capacitor value is selected for minimum output voltage ripple.

The converter is designed as per the designated parameters given in Table 2. The lithium nickel manganese cobalt (Li-NMC) battery is used for the experiment, whose parameters are given in Table 3. The inductor values are calculated to keep the converter in CICM operation even at low load conditions. The duty ratio (D) is calculated as $30 \%$ for an output voltage of $98 \mathrm{~V}$ with an input battery voltage of $48 \mathrm{~V}$. The switching frequency $\left(f_{\mathrm{s}}\right)$ of the converter is $15 \mathrm{kHz}$.
The minimal load for the PMBLDC motor constitutes the switching losses in VSI, copper, iron, and windage losses. Thus, a minimal burden of $40 \mathrm{~W}$ is considered for calculations.

$$
\begin{gathered}
V_{c o}=V_{o}=\frac{V_{i}}{(1-D)^{2}}, \\
V_{i} \times I_{L 1}=V_{o} \times I_{o} .
\end{gathered}
$$

No-load power $=40 \mathrm{~W}$. 


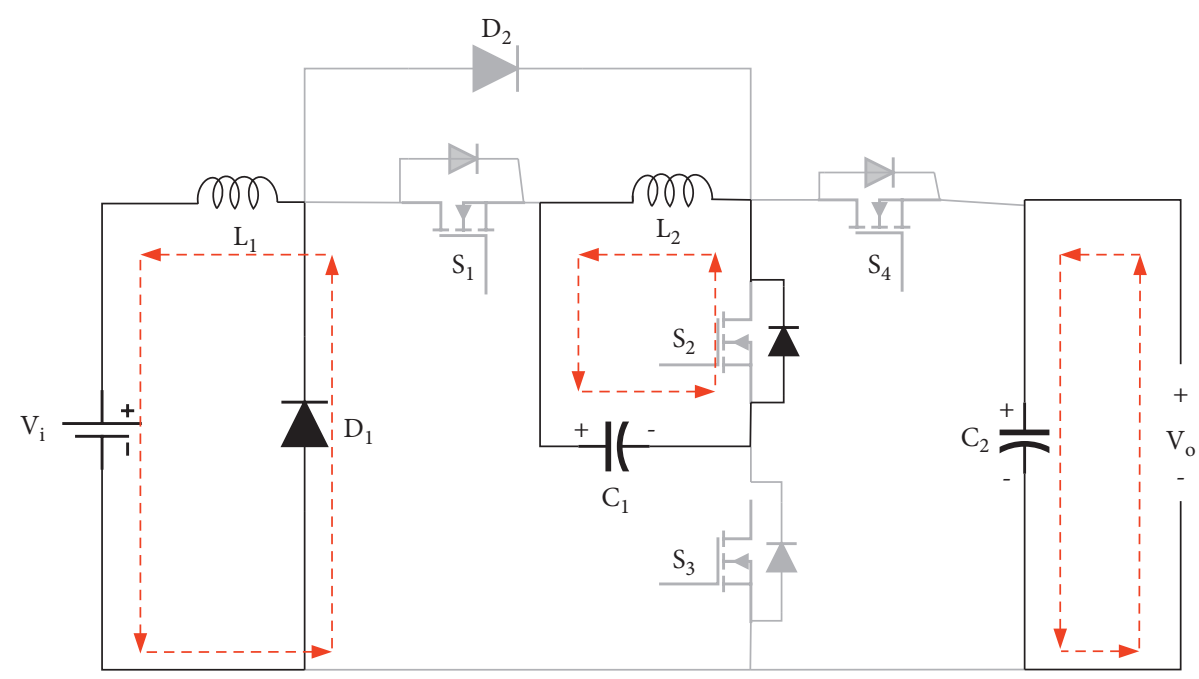

FiguRE 7: Converter buck mode operation in mode 2.

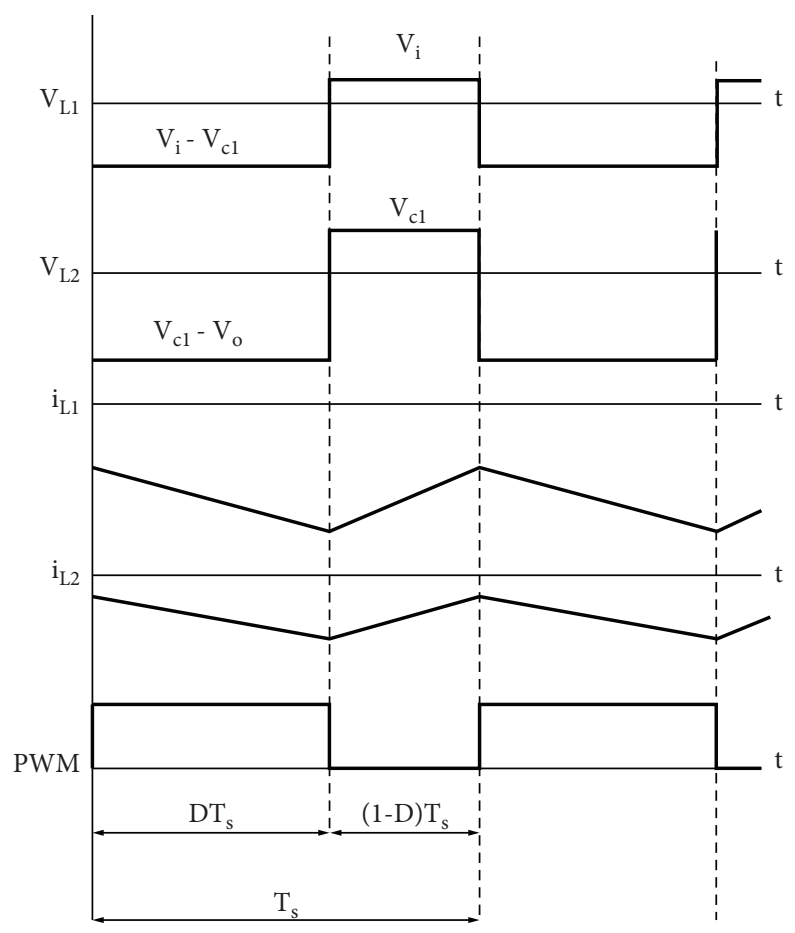

FIGURE 8: Converter's voltage and current waveform in buck mode.

$$
\begin{aligned}
I_{L 1} & =\frac{P_{\min }}{V_{i}}=0.8 A, \\
\Delta I_{L 1} & =1.6 A \\
V_{i} & =L_{1} \times \frac{\Delta I_{L 1}}{D T_{s}} .
\end{aligned}
$$

From (11), the value of input inductor $L_{1}$ is calculated as $0.6 \mathrm{mH}$. Thus, for CICM operation, a higher value of inductance, i.e., $1 \mathrm{mH}$, is selected in this work. The calculation for $L_{2}$ is done as follows:

$$
\begin{aligned}
& I_{L 1}=\frac{I_{o}}{(1-D)^{2}}, \\
& I_{L 2}=\frac{I_{o}}{(1-D)} .
\end{aligned}
$$

The calculated value of $I_{\mathrm{L} 2}$ at minimum load is $0.56 \mathrm{~A}$. Thus, the current ripple at boundary condition is $1.12 \mathrm{~A}$. 


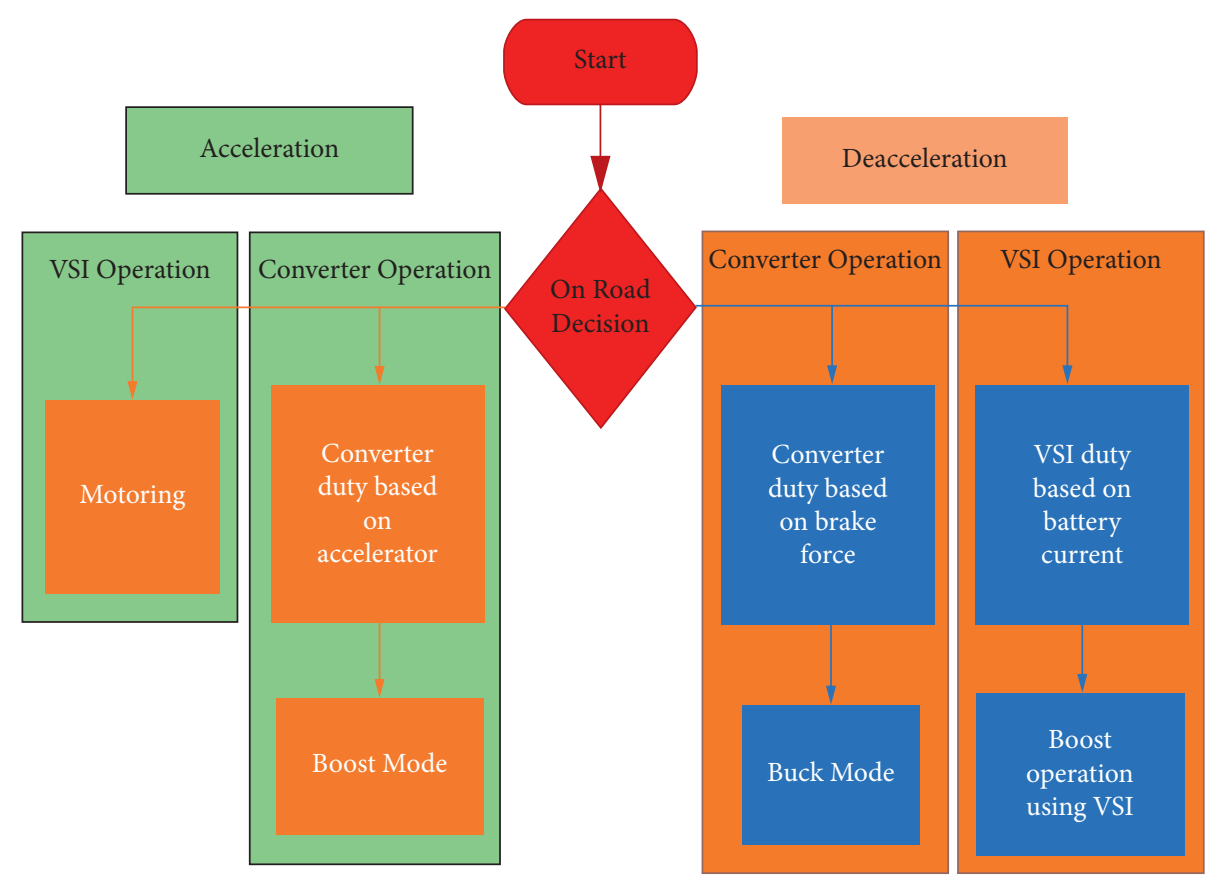

Figure 9: Flow diagram of the converter operation in EV.

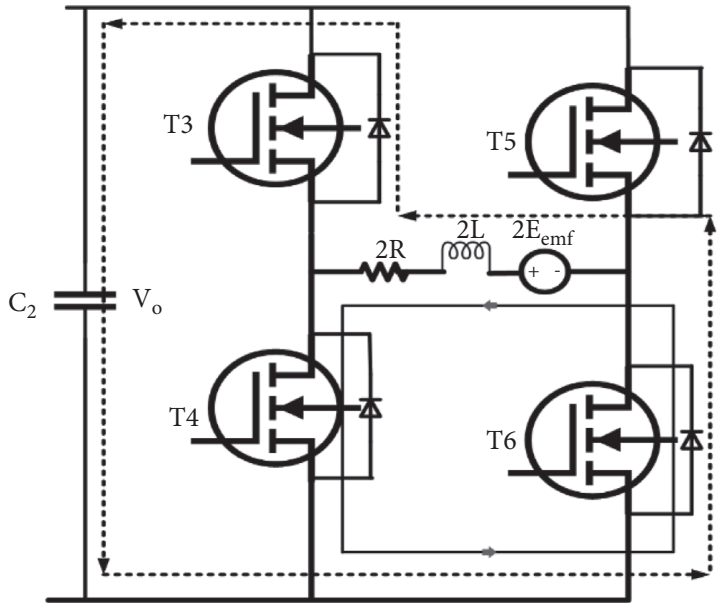

FIGURE 10: Equivalent circuit of two active phases of VSI during regenerative braking.

$$
\begin{aligned}
& V_{C 1}=\frac{V_{i}}{1-D}, \\
& V_{c 1}=L_{2} \times \frac{\Delta V_{L 2}}{D T_{s}} .
\end{aligned}
$$

The value of inductor $L_{2}$ is calculated using (15) as $1.2 \mathrm{mH}$. Thus, for CICM operation, a higher value of inductance, i.e., $1.5 \mathrm{mH}$, is selected in this work. The calculation for $C_{1}$ is as follows:

$$
\begin{aligned}
& I_{c}=C_{1} \times \frac{\mathrm{d} V_{c 1}}{\mathrm{~d} t}, \\
& I_{c}=-I_{L 2},
\end{aligned}
$$

$$
I_{L 2}=C_{1} \times \frac{\Delta V_{c 1}}{D T_{s}}
$$

Taking $\Delta V_{\mathrm{C} 1}=10 \%$ of $V_{\mathrm{C} 1}$, the value of capacitor $C_{1}$ is calculated as $43 \mu \mathrm{F}$. The readily available capacitor of $47 \mu \mathrm{F}$ is selected in this work.

$$
\begin{gathered}
I_{c o}=C_{2} \times \frac{\mathrm{d} V_{c o}}{\mathrm{~d} t}, \\
I_{L 2}-I_{o}=C_{2} \times \frac{\Delta V_{c o}}{(1-D) T_{s}} .
\end{gathered}
$$

For $\Delta V_{\text {co }}=2 \%$ of $V_{\text {co }}$ and $f_{s}=15 \mathrm{kHz}$, the value of $C_{2}$ is calculated as $102 \mu \mathrm{F}$. The commercially available capacitor with a higher value of $220 \mu \mathrm{F}$ is selected for this work. The calculated values of passive components in buck mode of operation are lower than that of boost mode operation. Thus, for the CICM operation of the converter, the boost mode values of passive components are selected for converter design.

The voltage stresses on switches $S_{1}, S_{2}$, and $S_{4}$ are calculated as

$$
\begin{aligned}
V_{S 1} & =\frac{V_{i}}{1-D}, \\
V_{S 2} & =V_{S 4} \\
& =\frac{V_{i}}{(1-D)^{2}} .
\end{aligned}
$$

The voltage stress on switches is low as compared to the converter in $[1,3]$.

With the help of equations (7)-(20) and the value of $V_{i}, V_{\mathrm{o}}$, and $I_{\mathrm{o}}$, all parameters, i.e., $L_{1}, L_{2}, C_{1}$, and $C_{2}$ can be calculated. The calculated parameters of the converter are given in Table 4. 


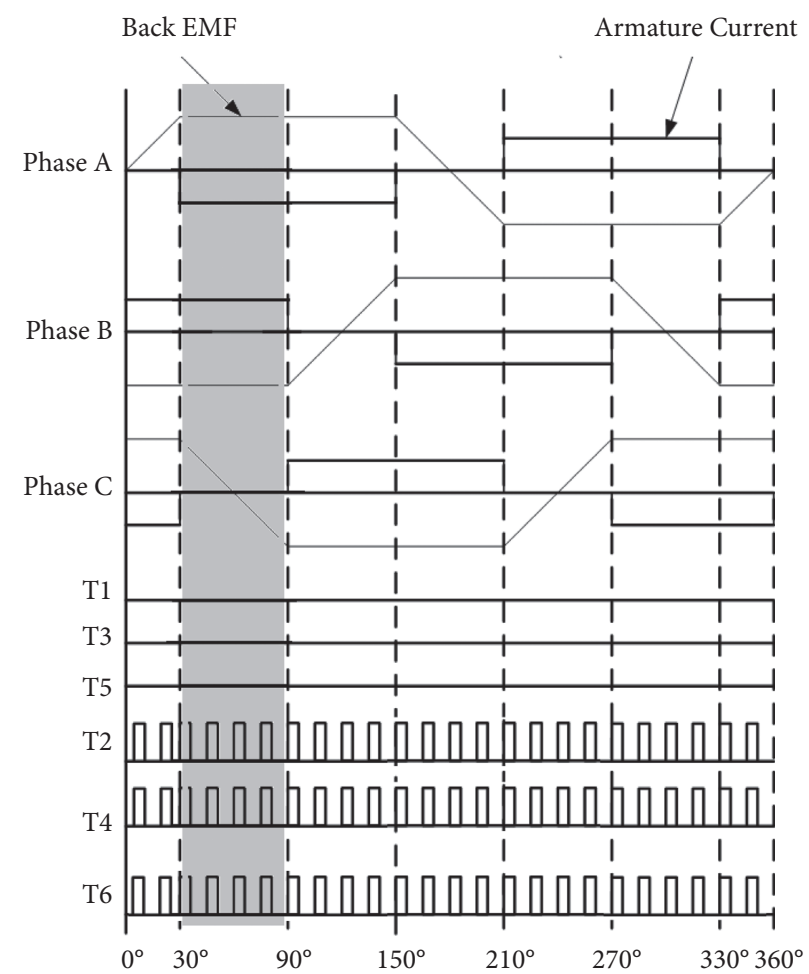

FIGURE 11: Switching signal of VSI during regenerative braking.

TABLE 2: Design parameters.

\begin{tabular}{|c|c|}
\hline \multicolumn{2}{|l|}{ Parameter } \\
\hline \multicolumn{2}{|l|}{$\begin{array}{l}\text { Input voltage }\left(V_{i}\right) \\
\text { Output power }\left(P_{\mathrm{o}}\right) \\
\text { Output voltage }\left(V_{\mathrm{o}}\right) \\
\text { Operating frequency }\left(f_{s}\right)\end{array}$} \\
\hline \multicolumn{2}{|c|}{ TABLE 3: Battery parameters. } \\
\hline Parameter & Value \\
\hline Type & Li-NMC \\
\hline Open circuit voltage & $52.5 \mathrm{~V}$ \\
\hline$\%$ SOC & $90 \%$ \\
\hline Ah rating & $25 \mathrm{Ah}$ \\
\hline Nominal discharge current & $10 \mathrm{~A}$ \\
\hline
\end{tabular}

\section{Simulation Results}

The bidirectional quadratic converter and VSI for the PMBLDC motor are simulated using the MATLAB/Simulink software package. The vehicular load is simulated by an inertial load of $0.1 \mathrm{~kg} \cdot \mathrm{m}^{2}$. The inertial load is connected to a PMBLDC motor having parameters, as given in Table 5 . The system is simulated for $7 \mathrm{~s}$ with $0-5 \mathrm{~s}$ in motoring mode and $5-7 \mathrm{~s}$ in regenerative mode. The intended regenerative action is observed as per the simulation results shown in this manuscript. The steady-state inductor currents with a gate driving signal in the converter's boost mode operation are shown in Figure 12.

In boost mode, when the switch is ON, both inductor's current increases, and when the switch is OFF, both

inductor's current decreases. In steady-state, the average value of current $i_{\mathrm{L} 1}$ is $3.3 \mathrm{~A}$, and current $i_{\mathrm{L} 2}$ is $2.35 \mathrm{~A}$, as shown in Figure 12. Figure 13 shows the steady-state output voltage $\left(V_{\mathrm{o}}\right)$, voltage $\left(V_{\mathrm{c} 1}\right)$ of capacitor $\mathrm{C}_{1}$, and battery voltage $\left(V_{i}\right)$ in boost (motoring) mode operation. In boost mode, the steady-state output voltage $V_{\mathrm{o}}$ is $98 \mathrm{~V}$, and capacitor $\left(\mathrm{C}_{1}\right)$ voltage $V_{\mathrm{c} 1}$ is $68.5 \mathrm{~V}$ with battery voltage $V_{i}=48 \mathrm{~V}$ at $30 \%$ duty ratio, as shown in Figure 13 .

The battery voltage $\left(V_{i}\right)$ and state of charge (SOC) are shown in Figure 14. It is depicted that during motoring (boost) mode, the battery SOC decreases, and a dip in battery voltage is observed during $0-5 \mathrm{~s}$ of simulation. At $t=5 \mathrm{~s}$, regenerative braking is applied; then, the converter starts to operate in buck mode, and battery voltage and SOC increase. In buck (regenerative braking) mode, the steady-state inductor currents are $I_{\mathrm{L} 1}=-5 \mathrm{~A}$ and $I_{\mathrm{L} 2}=-4 \mathrm{~A}$, respectively. The negative value of inductor currents means the current is flowing from load to source, as shown in Figure 15. Figure 16 shows the voltage stress on switches $S_{1}$ and $S_{2}$ during boost mode operation of the converter.

From time $0 \mathrm{~s}$ to time $5 \mathrm{~s}$, the motor speed in boost mode reached $2000 \mathrm{rpm}$. At $5 \mathrm{~s}$, regenerative braking is applied. As shown in Figure 17, the motor speed starts to decrease in 
TABLE 4: Converter parameters.

\begin{tabular}{lr}
\hline Parameter & Value \\
\hline$L_{1}$ & $1 \mathrm{mH}$ \\
$L_{2}$ & $1.5 \mathrm{mH}$ \\
$\mathrm{C}_{1}$ & $47 \mu \mathrm{F}$ \\
$\mathrm{C}_{2}$ & $200 \mu \mathrm{F}$ \\
\hline
\end{tabular}

TABLE 5: Motor parameters.

\begin{tabular}{lc}
\hline Parameter & Value \\
\hline Per phase resistance $\left(R_{\mathrm{a}}\right)$ & $1.09 \Omega$ \\
Per phase inductance $\left(L_{\mathrm{a}}\right)$ & $3.37 \mathrm{mH}$ \\
Voltage constant $(\mathrm{K})$ & $51.3 \mathrm{~V} / \mathrm{krpm}$ \\
Inertia $(\mathrm{J})$ & $0.00014 \mathrm{~kg} \mathrm{\textrm {m } ^ { 2 }}$ \\
Pole pair $(\mathrm{P})$ & 2 \\
\hline
\end{tabular}
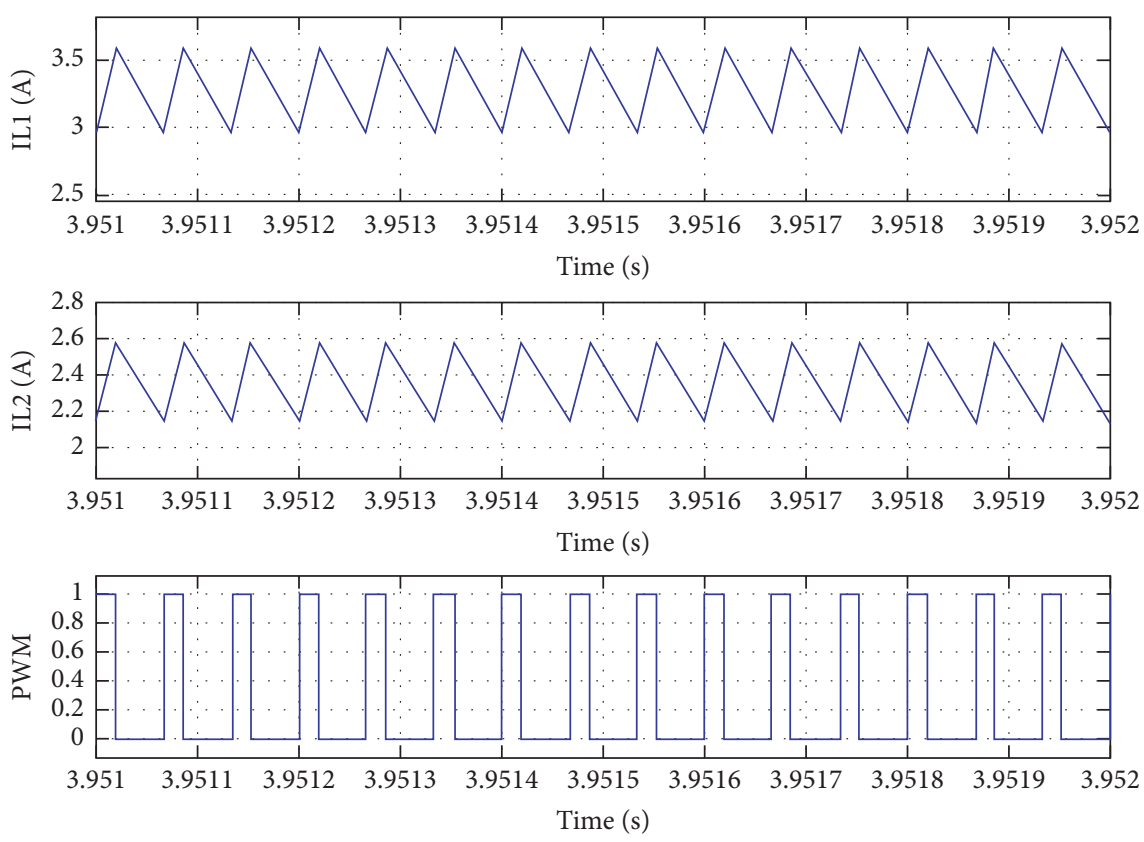

FIGURE 12: Inductor currents $I_{\mathrm{L} 1}$ and $I_{\mathrm{L} 2}$ with switching PWM during boost mode.

braking mode and reaches $650 \mathrm{rpm}$ in $7 \mathrm{~s}$. The performance of the PMBLDC motor under different levels of inertia is simulated in MATLAB. Regenerative braking is applied at different inertial loads, and energy is fed back into the battery from the stored energy of the inertial load. The plot between the percentage energy recovery and inertia is shown in Figure 18.

\section{Validation through Developed Prototype}

An experimental setup is developed to test the proposed system and the converter prototype. The system employs a 1.1 HP PMBLDC motor coupled with an inertia of the flywheel $\left(J=0.1 \mathrm{~kg} \quad \mathrm{~m}^{2}\right)$. The TMS320F28335 DSP microcontroller controls the developed DC-DC converter and the VSI in both the motoring and regenerative modes. Figure 19 shows the setup for the experimental verification of the proposed system.
A PMBLDC motor coupled with a high inertia flywheel is used to emulate the vehicular load. To reduce the impulse torque condition and safety of the system, a pulley belt system is employed for mechanical coupling of the motor and inertial load. Figure 20 shows different voltages, battery voltage, capacitor voltage $V_{\mathrm{c} 1}$, and output voltage in a steady state during boost mode operation of the converter at a $30 \%$ duty ratio. The steadystate inductor currents $I_{\mathrm{L} 1}, I_{\mathrm{L} 2}$, and switching PWM are shown in Figure 21 for boost mode operation. The waveforms and the values are confirmative of those obtained, as shown in Figure 12. Both the inductors charge during the $\mathrm{ON}$ time of the switch and discharge during the OFF time. The voltage stress on switches $S_{1}$ and $S_{2}$ during the boost mode of the converter is shown in Figure 22. Figure 23 shows the transition of the system operation from motoring to the RB mode. 

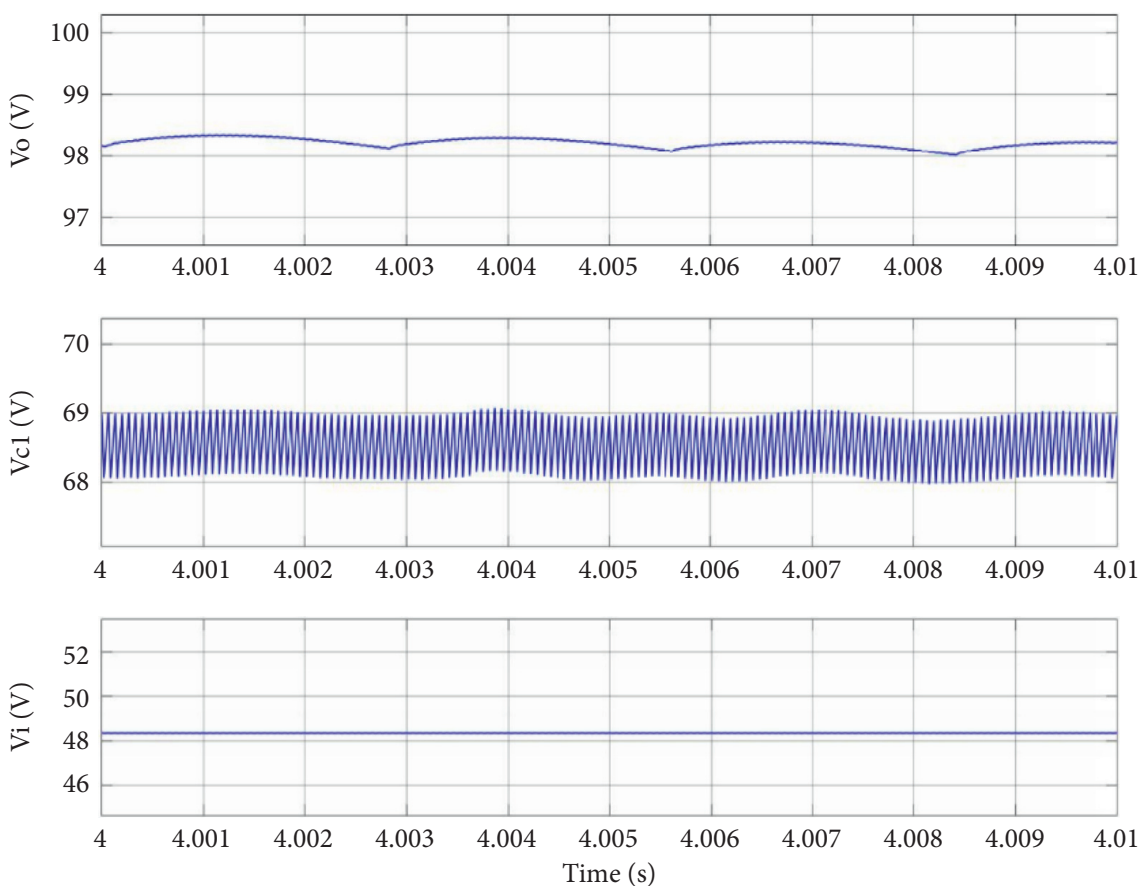

FIgURE 13: Output voltage $V_{\mathrm{o}}$, capacitor voltage $V_{\mathrm{cl}}$, and battery voltage $V_{i}$ during boost mode.
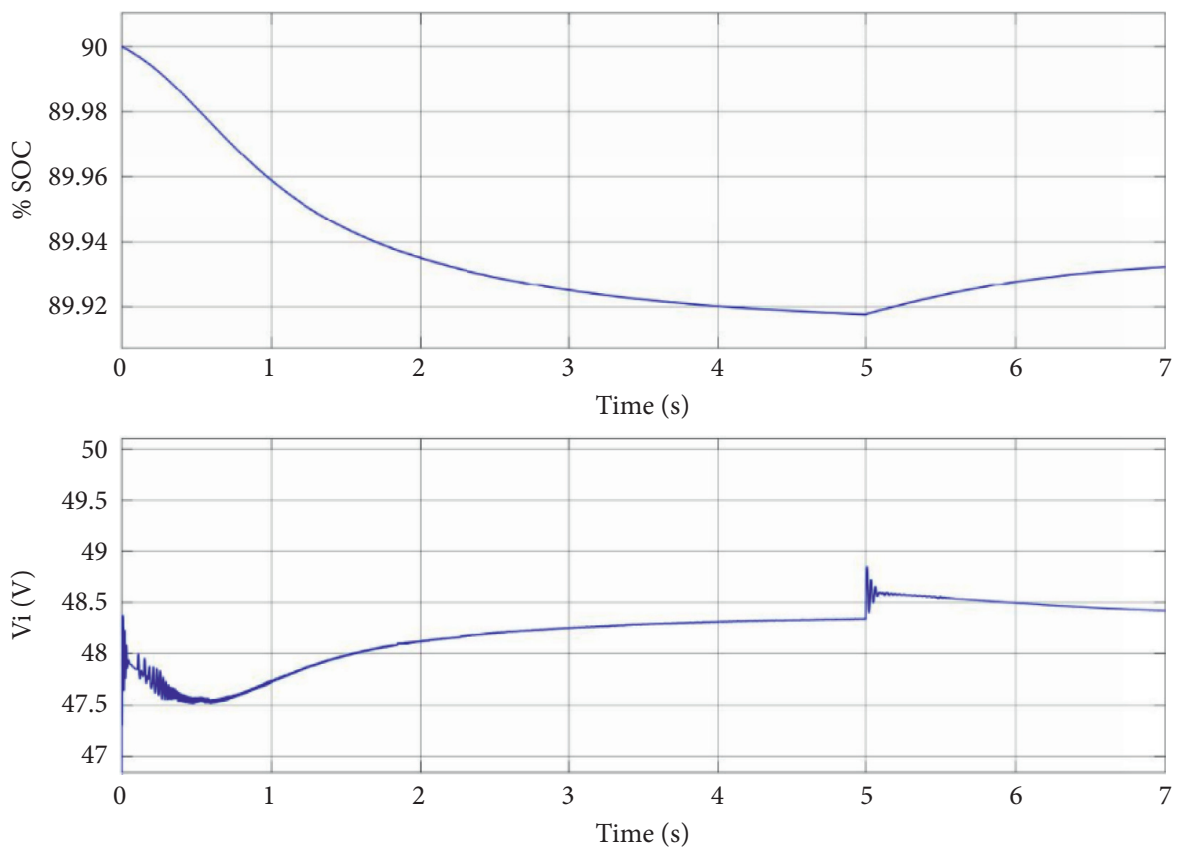

FIGURE 14: Battery voltage and \% SOC during motoring and regenerative braking.

The negative currents are indicative of the regenerative mode operation. During RB, the steady-state inductor currents $I_{\mathrm{L} 1}, I_{\mathrm{L} 2}$, and switching $\mathrm{PWM}$ are presented, as shown in Figure 24, aligned with those obtained in the simulation. It indicates the converter operation in the buck mode and the successful energy transfer from the PMBLDC motor to the battery. The value of inductor currents during $\mathrm{RB}$ is matched with the simulation result.

The continuous charging of the output capacitor due to VSI performing the boosting operation keeps the DC link voltage almost constant during the initial period of the braking process. The efficiency curve during boost mode is shown in Figure 25. 

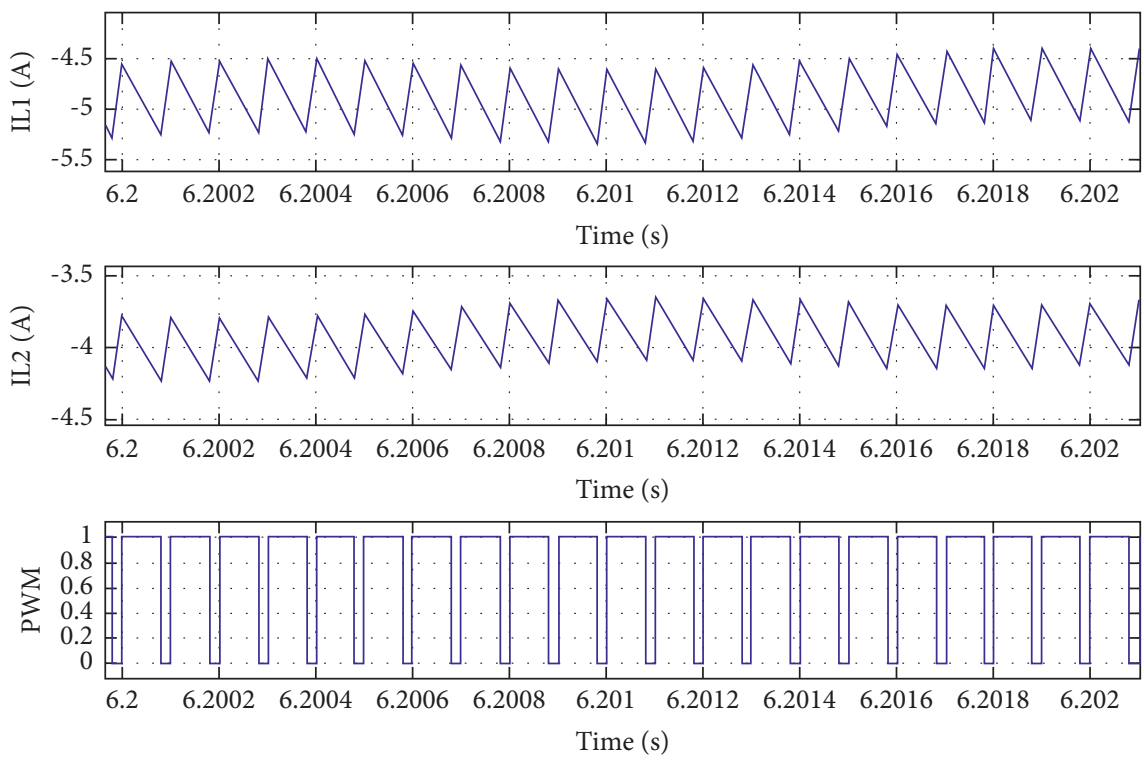

FIGURE 15: Inductor currents $I_{\mathrm{L} 1}$ and $I_{\mathrm{L} 2}$ with switching PWM during regenerative braking.

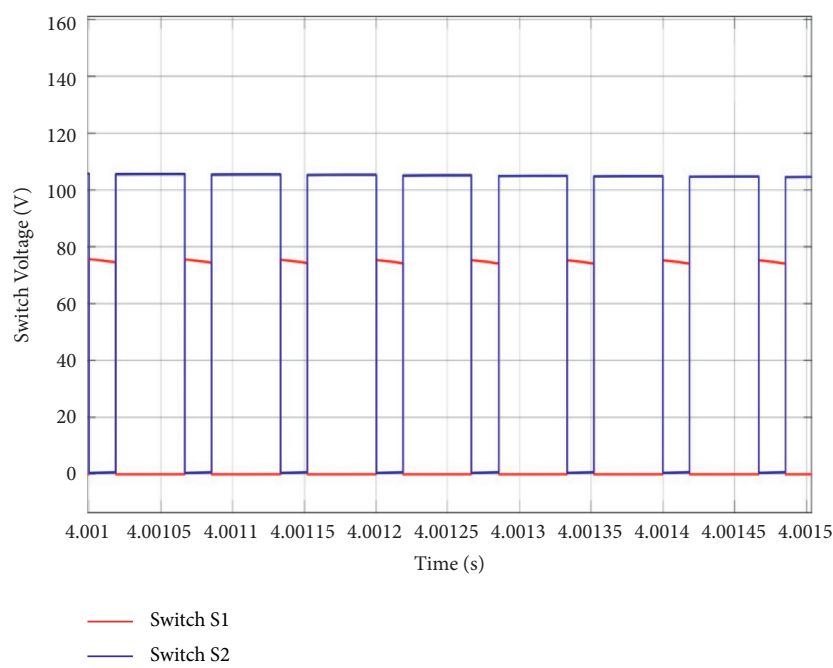

FIGURE 16: Voltage stress on switches $S_{1}$ and $S_{2}$ during boost mode operation of the converter.

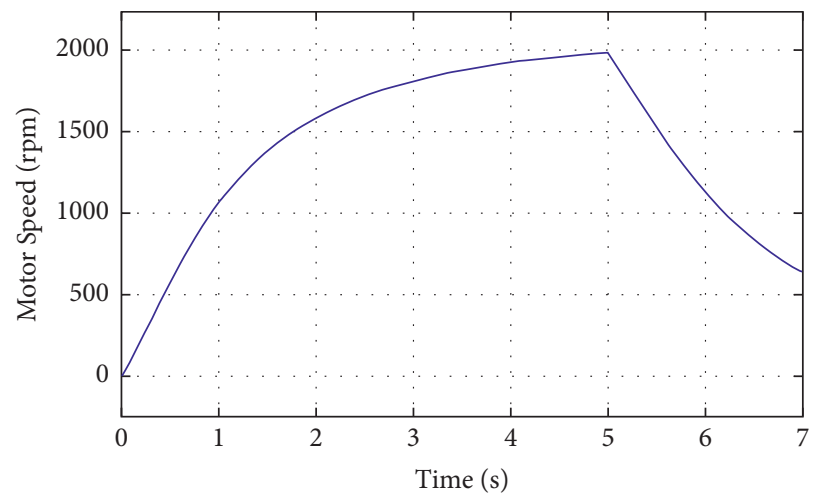

FIgURE 17: Motor speed characteristics during motoring and regenerative braking. 


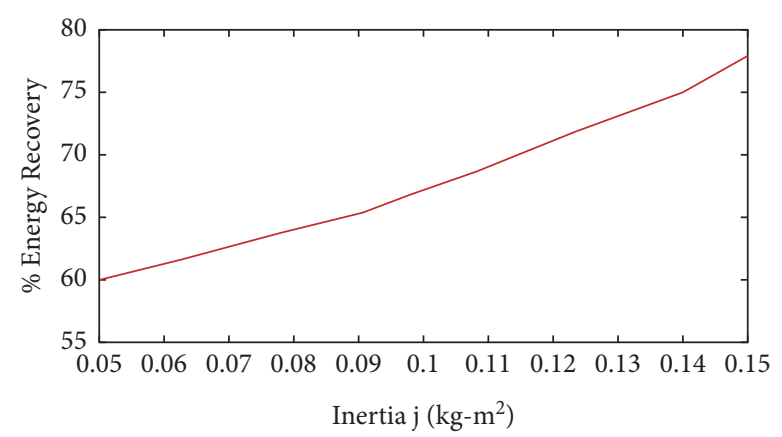

FIgURE 18: Plot of \% energy recovery vs. inertia $j\left(\mathrm{~kg} \mathrm{~m}^{2}\right)$.

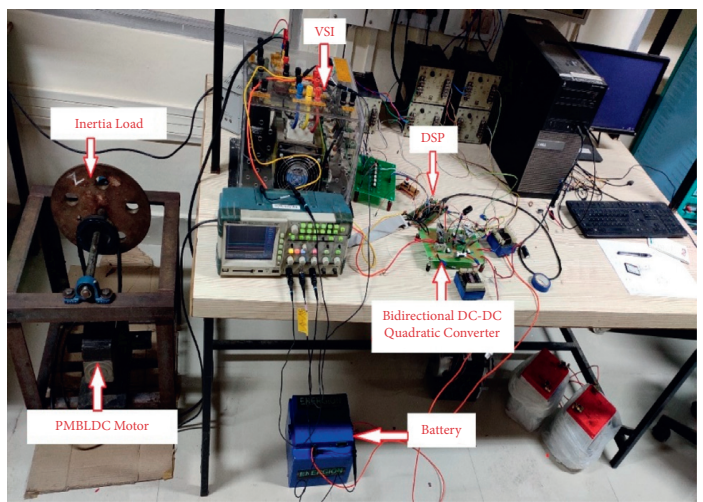

FIGURE 19: Hardware setup.

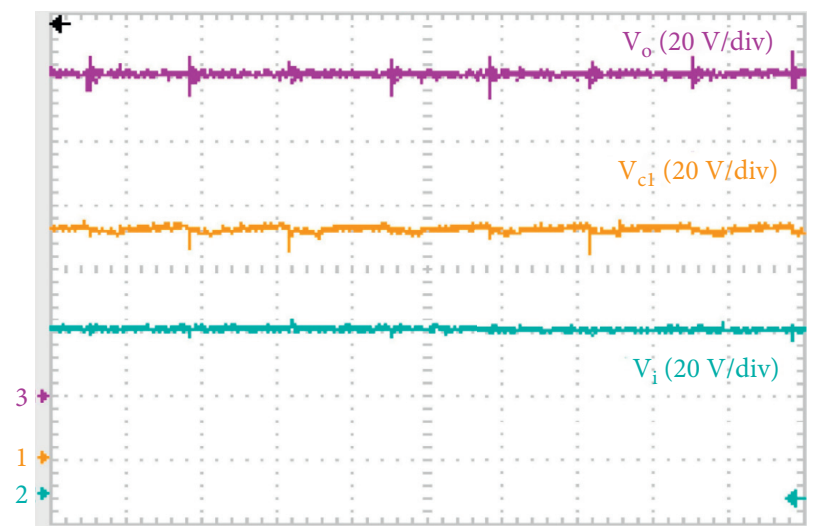

FIGURE 20: System voltages in steady-state boost operation of the converter: $V_{\mathrm{cl}}$ (channel 1); $V_{i}$ (channel 2); $V_{\mathrm{o}}($ channel 3). 


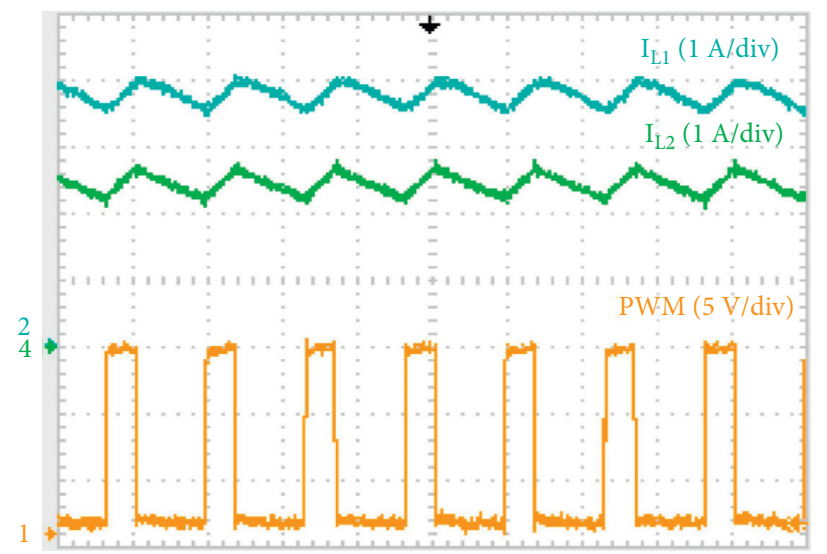

FIgURe 21: Boost mode operation of the converter: switching PWM (channel 1); $I_{\mathrm{L} 1}$ (channel 2); $I_{\mathrm{L} 2}$ (channel 4).

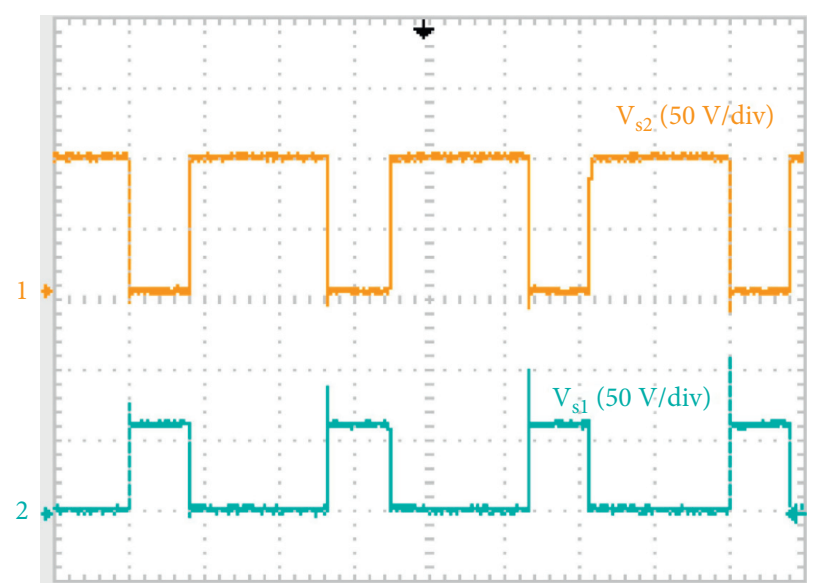

FIGURE 22: Voltage stress on switches $V_{\mathrm{S} 1}\left(\right.$ channel 2) and $V_{\mathrm{S} 2}$ (channel 1) in boost mode operation of the converter.

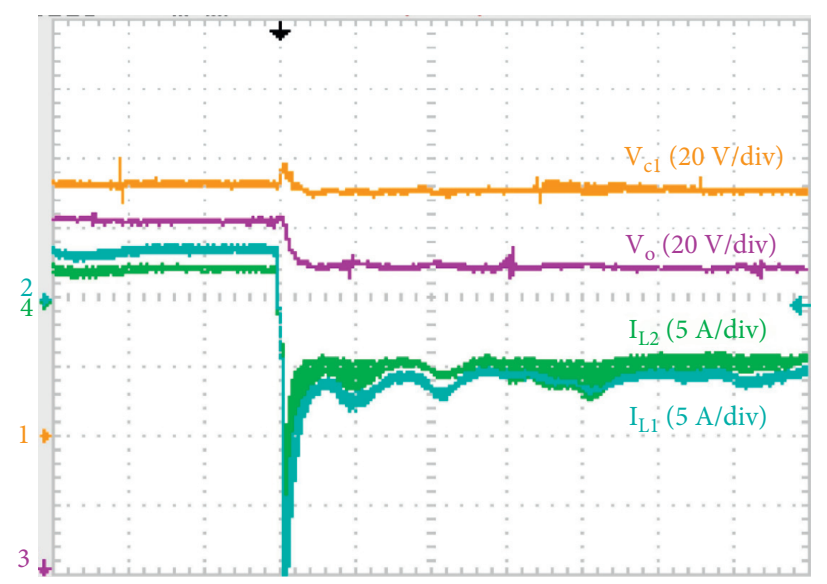

FIGURE 23: Transition of the motor from motoring mode to regenerative braking mode: $V_{\mathrm{c} 1}$ (channel 1); $I_{\mathrm{L} 1}(\operatorname{channel} 2) ; V_{\mathrm{o}}(\mathrm{channel} 3) ; I_{\mathrm{L} 2}$ (channel 4). 


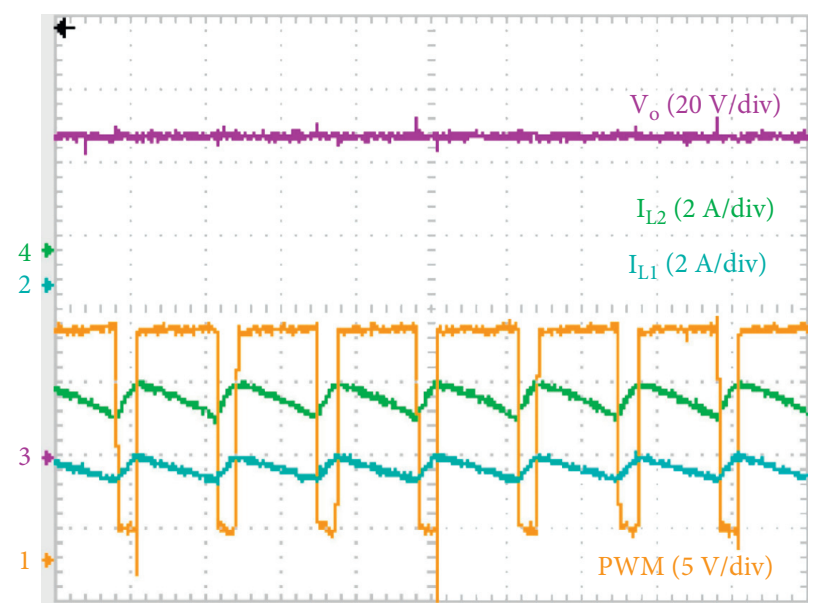

FIGURE 24: Buck mode operation of the converter: switching PWM (channel 1); $I_{\mathrm{L} 1}$ (channel 2); $V_{\mathrm{o}}$ (channel 3); $I_{\mathrm{L} 2}(\mathrm{channel} 4)$.

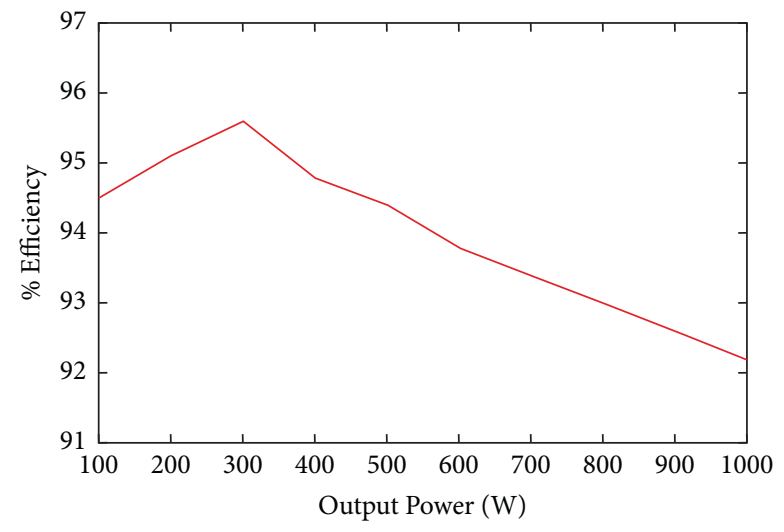

FIgURE 25: The curve between \% efficiency and output power during boost mode.

\section{Conclusion}

This study designs, develops, and tests a BDQC for RB application in LEV. The power flow direction is controlled successfully by changing the working mode of the VSI and the BDQC. The inertial load's mechanical energy is converted to electrical energy in the regenerative braking and fed back to the battery, as evident from the results. A control strategy is implemented to boost the back EMF of the PMBLDC motor by controlling the VSI and using the self-inductance of the motor. The bidirectional DC-DC quadratic converter operates at a maximum efficiency of $95.4 \%$ at a $30 \%$ duty ratio during boost mode operation. The implemented strategy and the system configuration proposed in this study have shown an economical and practical approach to eliminate the drawbacks of regenerative braking in the buck mode of BDC.

\section{Data Availability}

The data used to support the findings of this study are available from the author Mukesh Kumar upon request (email: mukeshk.rs.eee16@iitbhu.ac.in).

\section{Conflicts of Interest}

The authors declare that they have no conflicts of interest.

\section{Acknowledgments}

The authors thank the Electrical Machine and Drive Lab of the Department of Electrical Engineering at the Indian Institute of Technology (BHU), Varanasi, Uttar Pradesh, India, and the Department of Electrical and Computer Engineering, Hawassa University, Hawassa, Ethiopia.

\section{References}

[1] Z. Wang, P. Wang, B. Li, X. Ma, and P. Wang, “A bidirectional DC-DC converter with high voltage conversion ratio and zero ripple current for battery energy storage system," IEEE Transactions on Power Electronics, vol. 36, no. 7, pp. 80128027, 2021.

[2] P. S. Tomar, M. Srivastava, and A. K. Verma, "An improved current-fed bidirectional DC-DC converter for reconfigurable split battery in EVs," IEEE Transactions on Industry Applications, vol. 56, no. 6, pp. 6957-6967, 2020.

[3] S. Mousavinezhad Fardahar and M. Sabahi, "High step-down/ high step-up interleaved bidirectional DC-DC converter with low voltage stress on switches," IET Power Electronics, vol. 13, no. 1, pp. 104-115, 2020.

[4] W. Hassan, J. L. Soon, D. Dah-Chuan Lu, and W. Xiao, “A high conversion ratio and high-efficiency bidirectional DC- 
DC converter with reduced voltage stress," IEEE Transactions on Power Electronics, vol. 35, no. 11, pp. 11827-11842, 2020.

[5] Y. Raj Kafle, M. J. Hossain, and M. Kashif, "Quasi-Z-sourcebased bidirectional DC-DC converters for renewable energy applications," International Transactions on Electrical Energy Systems, vol. 31, Article ID e12823, 2021.

[6] B.-R. Lin and G.-Y. Wu, "Bidirectional resonant converter with half-bridge circuits: analysis, design, and implementation," Energies, vol. 11, 2018.

[7] Y. Xie, J. Sun, and J. S. Freudenberg, "Power flow characterization of a bidirectional galvanically isolated high-power DC/DC converter over a wide operating range," IEEE Transactions on Power Electronics, vol. 25, no. 1, pp. 54-66, 2010.

[8] Z. Yao and T. Liu, "Boost and full-bridge integrated converter for wide input-voltage range application," International Transactions on Electrical Energy Systems, vol. 31, Article ID e12916, 2021.

[9] T. F. Wu, Y. C. Chen, J. G. Yang, and C. L. Kuo, "Isolated bidirectional full-bridge DC-DC converter with a flyback snubber," IEEE Transactions on Power Electronics, vol. 25, no. 7, pp. 1915-1922, 2010.

[10] V. Cardoso, S. L. Brockveld Junior, T. B. Lazzarin, and G. Waltrich, "Double boost-flyback converter," IET Power Electronics, vol. 13, no. 6, pp. 1163-1171, 2020.

[11] S. Pal, B. Singh, and A. Shrivastava, "An efficient wide input wide output CrCM flyback converter in high-power LED lighting," International Transactions on Electrical Energy Systems, vol. 30, Article ID e12445, 2020.

[12] C.-M. Lai, J. Teh, Y.-C. Lin, and Y. Liu, "Study of a bidirectional power converter integrated with battery/ultracapacitor dual-energy storage," Energies, vol. 13, 2020.

[13] Y. Mei, Q. Jiang, H. Yang, W. Li, X. He, and S. Li, "Nonisolated stacked bidirectional soft-switching DC-DC converter with PWM plus phase-shift control scheme," Journal of Modern Power Systems and Clean Energy, vol. 5, no. 4, pp. 631-641, 2017.

[14] C. C. Lin, L. S. Yang, and G. W. Wu, "Study of a non-isolated bidirectional DC-DC converter," IET Power Electronics, vol. 6, no. 1, pp. 30-37, 2013.

[15] A. Sah, K. Chaudhary, and V. V. Ratnam, "Non-isolated multiphase buck-boost converter design for electric vehicle applications," in Proceedings of the 2014 Annual International Conference on Emerging Research Areas: Magnetics, Machines and Drives (AICERA/iCMMD), vol. 1-6, Kottayam, India, July 2014.

[16] M. Kumar, K. Kumar, and K. Chaudhary, "Modified nonisolated bidirectional DC-DC converter for regenerative braking for electric vehicle applications," in Proceedings of the Symposium on Power Electronic and Renewable Energy Systems Control, S. Mohapatro and J. Kimball, Eds., pp. 77-88pp. 77-, Bhubaneswar, India, December 2021.

[17] K. Choobdari Omran and A. Mosallanejad, "SMES/battery hybrid energy storage system based on bidirectional Z-source inverter for electric vehicles," IET Electrical Systems in Transportation, vol. 8, no. 4, pp. 215-220, 2018.

[18] E. P. Wiechmann, P. Aqueveque, R. Burgos, and J. Rodriguez, "On the efficiency of voltage source and current source inverters for high-power drives," IEEE Transactions on Industrial Electronics, vol. 55, no. 4, pp. 1771-1782, 2008.

[19] S. Rostami, V. Abbasi, N. Talebi, and T. Kerekes, "Three-port DC-DC converter based on quadratic boost converter for stand-alone PV/battery systems," IET Power Electronics, vol. 13, no. 10, pp. 2106-2118, 2020.
[20] A. R. Saxena and D. Kumar, "Transformerless high-gain battery-integrated DC-DC boost converter for fuel-cell stacks: design, analysis, and control," International Transactions on Electrical Energy Systems, vol. 31, Article ID e12722, 2021.

[21] M. Zaid, S. Khan, M. D. Siddique, A. Sarwar, J. Ahmad, and A. Iqbal, "A transformerless high gain dc-dc boost converter with reduced voltage stress," International Transactions on Electrical Energy Systems, vol. 31, Article ID e12877, 2021.

[22] G. Li, X. Jin, X. Chen, and X. Mu, "A novel quadratic boost converter with low inductor currents," CPSS Transactions on Power Electronics and Applications, vol. 5, no. 1, pp. 1-10, 2020.

[23] V. F. Pires, A. Cordeiro, D. Foito, and J. F. Silva, "Control of bidirectional quadratic DC-DC converters for storage support of DC power grids," in Proceedings of the 2018 7th International Conference on Renewable Energy Research and Applications (ICRERA), pp. 227-232, Paris, France, October 2018.

[24] S.-W. Lee and H.-L. Do, "Quadratic boost DC-DC converter with high voltage gain and reduced voltage stresses," IEEE Transactions on Power Electronics, vol. 34, no. 3, pp. 23972404, 2019.

[25] X. Nian, F. Peng, and H. Zhang, "Regenerative braking system of electric vehicle driven by brushless DC motor," IEEE Transactions on Industrial Electronics, vol. 61, no. 10, pp. 5798-5808, 2014.

[26] F. Naseri, E. Farjah, and T. Ghanbari, “An efficient regenerative braking system based on battery/supercapacitor for electric, hybrid, and plug-in hybrid electric vehicles with BLDC motor," IEEE Transactions on Vehicular Technology, vol. 66, pp. 3724-3738, 2017.

[27] K. A. Singh and K. Chaudhary, "Design and development of a new three-phase AC-DC single-stage wind energy conversion system," IET Power Electronics, vol. 14, no. 2, pp. 302-312, 2021. 